\title{
Retrospective analysis of poisoning cases admitted in a tertiary care hospital in North Eastern UP, India
}

\author{
Singh RR ${ }^{1}$, Kumar $A^{2}$, Uraiya $D^{3}$, Dhaon $\mathbf{P}^{4}$ \\ ${ }^{1}$ Dr. R. R. Singh, Assosciate Professor, ${ }^{2}$ Dr. Anoop Kumar, Assistant Professor, ${ }^{3}$ Dr. Dharmendra Uraiya, Assistant \\ Professor, ${ }^{4}$ Dr. Pooja Dhaon, Assistant Professor. All are affiliated with Department of Medicine, Hind Institute of \\ Medical Sciences, Barabanki, UP, India.
}

Address for Correspondence: Dr. R.R. Singh, Email: Singhravneesh@gmail.com

\begin{abstract}
Aims: Poisoning is a medical emergency associated with significant morbidity and mortality. This study was done to analyse the pattern of poisoning cases coming to our tertiary care centre located in the north eastern part of U.P., India. It is important to know the pattern of poisoning in a region so as to take proper actions for prevention and management of the cases. Methods: This was a retrospective hospital record based study of poisoning patients who were admitted to our tertiary care hospital between July, 2014 to December 2015. Data of total 140 cases were analyzed for demography, type of poisoning and outcome and results were analyzed statistically. Results: Pesticides dominated the picture amongst the rural population while urban people consumed drugs and household agents. The overall mortality rate was $4.28 \%$. Most of the deaths were in Aluminium phosphide cases $(66.66 \%)$ followed by paraquat and organochlorine. Conclusion: In adults poisoning is mostly suicidal while children accidentally ingest substances. Pesticides, chemicals and drugs available in house are mostly used. Rural people resort to pesticides while urban population takes household articles or drugs for self harm. Mortality depends on the type of poison, amount consumed and the time lapsed in reaching a health care facility as well as how equipped is the health care facility to tackle the poisoning cases.
\end{abstract}

Keywords: Poisoning, Pesticides, Peppermint oil, Diesel plant.

\section{Introduction}

Poisoning is a worldwide problem. According to World Health Organization (WHO) estimates 0.3 million people die every year due to various poisoning agents [1]. The profile of poisoning patients and the choice of agents greatly vary between countries.

Aanalgesics, tranquillizers and antidepressants are the commonly used agents for self-poisoning in industrialized countries [2]. Whereas in less developed agriculture dominant countries, pesticides are used often [3]. As most of the population of India lives in villages, studies have revealed that pesticides are the commonly used agents for self harm in India [4]. However, poisoning patterns may even vary within a country especially when comparing wealthier urban population with poor rural population according to ease of availability of a particular agent.

Manuscript received $4^{\text {th }}$ June 2016

Reviewed: $13^{\text {th }}$ June 2016

Author Corrected: $25^{\text {th }}$ June 2016

Accepted for Publication $12^{\text {th }}$ July 2016
Knowledge of general pattern of poisoning in a particular region can help in early diagnosis and treatment, thus contributing to a decrease in mortality and morbidity. Therefore, with the aim of determining the socio-demographic profile and to identify the important poisons used for self-harm in our region, the present study was conducted on cases admitted to a tertiary care hospital in Barabanki, located in the north eastern region of U.P., India.

\section{Methods}

The study was conducted in Hind Institute of Medical Sciences, Safedabad, Barabanki; a tertiary care hospital in the north eastern region of U.P., India. It caters to both the rural and urban population of the district. Relevant data was collected retrospectively from the patient records of the emergency and ICU between July, 2014 to December 2015. Permission was taken from the ethical committee of the Institute to allow us to access 
the information from the patient's case sheets in the record section for the purpose of the research. Cases of snake and scorpion bites and food poisoning were excluded from the study. Patient data regarding age, gender, domicile, socio-economic status, time elapsed after consumption of poison, type of poison, mode of poisoning, associated psychiatric illness and outcome was collected in pre-structured proforma. The data was analyzed for the pattern and prevalence of different poisons in the region.

\section{Results}

In the present study, 140 poisoning cases who presented to our institute were retrospectively analyzed (Table 1). The results showed high male predominance $(61.42 \%)$ as compared to females $(38.57 \%)$. Predominantly poisoning cases were from the rural areas (72.85\%). Maximum number of poisoning cases were of age group of 21-30 yrs. (38.57\%) followed by age group of 31-40 yrs (32.14\%), >40 yrs (21.42\%), 11-20yrs (5\%), <10yrs (2.85\%). Most of the cases were from rural population $(72.85 \%)$. We found that in our study, people who took poison belonged predominantly to low socio-economic status $(72.85 \%)$, followed by $22.85 \%$ of medium and $4.28 \%$ of high socio-economic status. Amongst our cases suicidal mode was found in $92.14 \%$ of cases followed by accidental $(7.86 \%)$. Accidental poisoning was more common in younger age group.

Time of presentation to hospital after taking poison was within $2 \mathrm{hrs}$ in only $27.85 \%$ cases, between $2-4 \mathrm{hrs}$ in $19.28 \%$, between 4-6 hrs in $31.42 \%$ and more than $6 \mathrm{hrs}$ in $21.42 \%$ cases (Table 2). One of our patients with Paraquat poisoning came late to us in $72 \mathrm{hrs}$ to us as it was being treated by doctors in the periphery as viral respiratory tract infection.

Regarding the agents used (Table 3), pesticides topped the list (65\%). Amongst the pesticides, we had 69 cases of organophosphorous compounds, 16 cases of carbamate, one case of organochlorine and 5 cases of aluminium phosphide poisoning. Amongst the herbicides, there was one case of poisoning due to Paraquat.

Among plant products, we had 10 cases of peppermint oil, 1 of dhatura, 2 of cannabis and 4 of Jatropha curas) (diesel plant) poisoning. Both Dhatura and Jatropha were accidentally ingested. Dhatura presented with anti-cholinergic syndrome while Jatropha led to vomiting, diarrhoea, pain in abdomen and miosis.

Table-1: Characteristics of poisoning patients.

\begin{tabular}{|l|c|}
\hline Patient characteristics & $\mathrm{N}=140$ \\
\hline Sex & $86(61.42 \%)$ \\
\hline Males & $54(38.57 \%)$ \\
\hline Females & \\
\hline Age(years) & $4(2.85 \%)$ \\
\hline Less than 10 & $7(5 \%)$ \\
\hline $11-20$ & $54(38.57 \%)$ \\
\hline $21-30$ & $45(32.14 \%)$ \\
\hline $31-40$ & $30(21.42 \%)$ \\
\hline$>40$ & \\
\hline Socioeconomic status & $102(72.85 \%)$ \\
\hline Low & $32(22.85 \%)$ \\
\hline Medium & $6(4.28 \%)$ \\
\hline High & \\
\hline Urban and Rural Distribution of cases & $102(72.85 \%)$ \\
\hline Rural & $38(27.14 \%)$ \\
\hline Urban & \\
\hline Mode of Poisoning & $129(92.14 \%)$ \\
\hline Suicidal & $11(7.86 \%)$ \\
\hline Accidental & \\
\hline
\end{tabular}


Table-2: Time elapsed since exposure to hospital arrival and mortality.

\begin{tabular}{|l|c|c|}
\hline Time of presentation after consumption & Total cases & Expired cases $(\%)$ \\
\hline Less than 2 hours & $39(27.85 \%)$ & nil \\
\hline 2-4 hours & $27(19.28 \%)$ & $1(3.7)$ \\
\hline 4.5-6 hours & $44(31.42 \%)$ & $2(4.5)$ \\
\hline More than 6 hours & $30(21.42)$ & $3(10)$ \\
\hline Total & $\mathbf{1 4 0}$ & $\mathbf{6 ( 4 . 2 8 )}$ \\
\hline
\end{tabular}

Table-3: Agents consumed and rural vs. urban distribution.

\begin{tabular}{|c|c|c|c|c|c|c|}
\hline \multirow[t]{2}{*}{ Poison Abused } & \multicolumn{4}{|c|}{ Residence } & \multicolumn{2}{|c|}{$\mathrm{N}=140$} \\
\hline & Rural & $\%$ & Urban & $\%$ & Total cases & $\%$ \\
\hline \multicolumn{7}{|l|}{$>$ Pesticides :- } \\
\hline 1-Organophosphorous Compounds & 59 & 85.5 & 10 & 14.4 & 69 & 49.28 \\
\hline 2- Organochlorines & 1 & 100 & 0 & 0 & 1 & 0.7 \\
\hline 3- Carbamate & 14 & 87.5 & 2 & 12.5 & 16 & 11.42 \\
\hline 4- Aluminium Phosphide & 4 & 80 & 1 & 20 & 5 & 3.5 \\
\hline \multicolumn{7}{|l|}{$>$ Herbicide :- } \\
\hline 1- Paraquat & 1 & 100 & 0 & 0 & 1 & 0.7 \\
\hline $\begin{array}{l}>\text { Insect Repellant :- } \\
\text { 1-Mortein }\end{array}$ & 0 & 0 & 3 & 100 & 3 & 2.1 \\
\hline \multicolumn{7}{|l|}{$>$ Drugs :- } \\
\hline 1- Benzodiazepines & 0 & 0 & 5 & 100 & 5 & 3.5 \\
\hline 2- Anti-Depressants & 0 & 0 & 2 & 100 & 2 & 1.4 \\
\hline \multicolumn{7}{|l|}{$>$ Plants Products :- } \\
\hline 1- Dhatura & 1 & 100 & 0 & 0 & 1 & 0.7 \\
\hline 2- Cannabis & 1 & 50 & 1 & 50 & 2 & 1.4 \\
\hline 3- Jatropha Curcas (Diesel Plant) & 4 & 100 & 0 & 0 & 4 & 2.8 \\
\hline \multicolumn{7}{|l|}{$\begin{array}{l}\text { R Rat Poision :- } \\
\text { 1- Zinc Phosphide }\end{array}$} \\
\hline 1- Zinc Phosphide & & & & & & \\
\hline \multicolumn{7}{|l|}{$>$ House hold agents :- } \\
\hline 1- Phenyl & 0 & 0 & 1 & 100 & 1 & 0.7 \\
\hline 2-Kerosene & 1 & 100 & 0 & 0 & 1 & 0.7 \\
\hline$>$ Miscellaneous & 0 & 0 & 1 & 100 & 1 & 5.7 \\
\hline 1- Alcohol & & 2222 & 8 & & & \\
\hline 2- Peppermint Oil & 4 & 33.33 & 8 & 06.06 & 12 & 8.5 \\
\hline & 10 & 100 & 0 & 0 & 10 & 7.14 \\
\hline
\end{tabular}

Table-4: Psychiatric analysis of Suicidal Poisoning.

$\mathrm{N}=129$

\begin{tabular}{|l|c|c|}
\hline Psychiatric illness & Cases & \%age \\
\hline Reactive Depression & 71 & 55.03 \\
\hline Chronic alcoholism & 25 & 19.37 \\
\hline Psychotic disorder & 3 & 2.32 \\
\hline Social and financial stress & 14 & 10.85 \\
\hline Crisis in interpersonal adjustments & 16 & 12.40 \\
\hline Total & $\mathbf{1 4 0}$ & \\
\hline
\end{tabular}


Patients who came from city consumed household agents, drugs and insect repellent fluids (Table 3). Among drugs, 5 cases took benzodiazepines and 2 took anti-depressants for self harm. The age group was above 30 yrs. These were people who were either taking these drugs for sleeping or were under treatment for depression.

The total mortality of poisoning cases in our study period was $6(4.28 \%)$. The patients who succumbed to poisoning were four of aluminium phosphide poisoning and one each of organochlorine and paraquat poisoning. The patient with paraquat poisoning had come late to our facility and succumbed to refractory respiratory failure. Patients with aluminium phosphide had severe metabolic acidosis and refractory respiratory failure while that with organochlorine poisoning had intractable seizures and respiratory failure.

On psychiatric analysis of patients, most had reactive depression (55.03\%), chronic alcoholism (19.37\%), psychotic disorder $(2.32 \%)$, social and financial stress $(10.85 \%)$ and crisis in interpersonal adjustments was present $(12.40 \%)$. (Table 4)

\section{Discussion}

In our present study we observed a high male predominance $(61.42 \%)$ as compared to females $(38.57 \%)$. Higher suicides rates among men have been reported in other Indian studies too. [5, 6, 7] This may be due to males being more exposed to stress and strain and competition in the modern era. Low socioeconomic status, unemployment and inability to live up to the expectations of others in the rapid urbanizing society could be contributing factors for higher suicide rate among men [8].

As bread earning age groups of 21-30 years and 31-40 years outnumbered other age groups in self harm, this is of grave concern. Several social stressors like problems in achieving educational goals, recruitment in service, settlement in marriage and other life settlement factors [5] play a crucial role in impulse behaviour under which many of them commit suicides.

Time of presentation to hospital after taking poison is also an important factor. Only $27.85 \%$ cases presented within $2 \mathrm{hrs}$. This may be due to lack of transportation facilities in the rural set up. Lack of knowledge of toxicology of various poisons is another factor as one of our patients with Paraquat poisoning came in 3 days (72 hrs) to us as it was being treated in the periphery as respiratory tract infection before coming to us. Similarly the case with organochlorine poisoning had come at $8 \mathrm{hrs}$ after ingestion. Time lapse has a significant impact on mortality beside the agent taken. As the time to reach health care set up increases, morbidity and mortality increases. Similarly Ramesha et al [9] also observed that apart from type of poison, issue of greater time lag in reaching health care setup also is decisive for prognosis. This suggests that primary health care centres should be equipped for treating poisoning cases and secondly if they are referred, it should be as early as possible.

Regarding the agents used, pesticides topped the list $(65 \%)$ as Barabanki being mostly an agricultural area, agrochemicals are easily available. The overall mortality was $4.28 \%$. The low mortality $(4.28 \%)$ in our study reflects that good poisoning management at a tertiary care centre can change the prognosis in most of the cases. Similar conclusion regarding good poisoning management by skilled staff at a tertiary care hospital and low mortality was drawn by Leena et al [10].

However, there was higher mortality among aluminium phosphide poisoning cases. This simply indicates its highly toxic nature as well there was delay in reaching the hospital. One who survived had taken exposed tablets. Any specific antidote for aluminium phosphide is not yet available. Moreover, it was consumed mostly by young people who were bread earners in their family. Therefore authors suggest that it should be banned and substituted by less toxic pesticides. Also research needs to be done to find some antidote for this lethal poison. The other cases who succumbed were one due to organochlorine and another due to paraquat poisoning. The patient with paraquat poisoning succumbed to intractable respiratory failure.

We had 10 cases of Peppermint oil intake. This oil is extracted from the plant Mentha piperita [11] and is widely cultivated in Barabanki. The oil is extracted by steam distillation [11] from the plant. Menthol, the active ingredient in peppermint oil is rapidly absorbed. The clinical features on presentation were flushing, strong smell of mint from the body, bradycardia, nausea, vomiting and severe burning like sensation in 
the epigastrium (probably due to unique cooling property of menthol). Two patients who took toxic dose of the oil orally went into coma and shock with cold peripheries for which they had to be intubated and respiratory and ionotropic support was given. Soumya $\mathrm{S}$ Nath [12] also reported near fatal toxicity of peppermint oil. There is no specific antidote for peppermint oil and management is supportive [12] Peppermint oil has been used for medicinal uses from hot flushes to irritable bowel syndrome, nausea and indigestion [11] but an overdose or suicidal consumption can be serious. It is consists mainly of menthol (35-60\%) and menthone (15\% to $30 \%$ ), but also contains pulegone, which can have central effects on the cardio-respiratory and neural centres [12] leading to fatal consequences.Further research is needed to study the toxic effects of this compound.

Among plant products, Jatropha curas (Diesel plant)poisoning needs discussion.The ingestion of Jatropha was accidentally by village children playing near the plant. They were attracted by the black seeds which were sweet to taste and swallowed them out of curiosity. They presented with vomiting, diarrhoea, pain in abdomen along with constricted pupils. This picture comes in the differential diagnosis of organophosphorous poisioning. But in these cases their parents brought the sample of seeds which they had consumed.As their is no definitve antidote of Jatropha, children were managed conservatively with gastric lavage, IV fluid support and antiemetics. They were stable within $6 \mathrm{hrs}$ and were discharged the next day.Kulkarni et al [13] have reported GI symptoms while Koltin et al [14] have also reported miosis in such cases.

Amongst those who consumed household agents, drugs and insect repellent fluids were city dwellers due to easy availability in the house. Drugs which were used were benzodiazepines anti-depressants. The age group was above 30 yrs. These were people who were either taking these drugs for sleeping or were under treatment for depression.

In our setup there was a greater preponderance of suicidal cases as compared to accidental. Many cases of self harm are due to impulsive actions in response to trivial situations. Psychiatric analysis of suicidal patients revealed that reactive depression, chronic alcoholism, psychotic disorder, social and financial stress and crisis in interpersonal adjustments are major associated issues. High degree of stress in academic, financial and social sectors as well as inability to achieve targets on professional, educational and socioeconomic fronts leading to limited alternatives are the usual contributory factors for suicidal self harm [9]. Those suffering from psychiatric ailments with suicidal behaviour should have proper treatment under a psychiatrist. Agents used for poisoning depend also on the ease of availability of those agents. So easy access to harmful substances need to be minimized to save our young generation. Accidental poisoning was more common in children. Same was observed by Ramesha et al [9] Ignorance about proper storage in households was the reason for the accidental cases except in four cases of accidental ingestion of Jatropha Curcas (Diesel plant) seeds by children playing near the plants. Proper education about storage of chemicals and their lethal potential need to be given to the masses as well more attention to the mental health and psychosocial interventions are needed to reduce the self harm incidents.

Changes in farming practice such as integrated pest management (IPM) [15] and industry initiatives in reducing the pesticide hazards are some of the possible measures. There is also an International Code of Conduct on the distribution and use of pesticides [16]. This necessitates government authorities of countries to establish regulations and voluntary standards of conduct on the safe distribution, handling and availability of pesticides [10]. Implementation of the code needs good infrastructure and resources, backed by a strong political will to prevent pesticide hazards [10].

Also proper transportation of the patient to a health facility is needed at the earliest as time lag to proper medical care has important bearing on the prognosis in poisoning. Trained persons should be available at these centres to deal with poisoning .Regular refresher courses on toxicological emergencies should be done for medical officers working in primary and secondary health centres.

\section{Conclusion}

Our study shows that despite their being many poisonous substances, people use the agent which is readily available in their locality. Rural population usually resorted to pesticides while urban population consumed drugs and household chemicals for self harm. We had good number of cases of Peppermint oil poisoning as Mentha piperita, is grown extensively in our area. The important factors influencing prognosis in 
poisoning were the type of poison, the amount taken and the time lag between presentation to hospital. Social education and awareness, safe use initiatives and legislation on availability of harmful pesticides and drugs is needed to control this major health problem. And those with psychiatric diseases should have proper treatment to prevent recurrence.

Funding: Nil, Conflict of interest: None initiated.

Permission from IRB: Yes

\section{References}

1. Thundiyil JG, Stober J, Besbelli N, Pronczuk J. Acute pesticide poisoning: a proposed classification tool. Bull World Health Organ. 2008 Mar;86(3):205-9.

2. McClure GM. Suicide in children and adolescents in England and Wales 1970-1998. Br J Psychiatry. 2001 May;178:469-74.

3. Marecek J. Culture, gender, and suicidal behavior in Sri Lanka. Suicide Life Threat Behav. 1998 Spring; 28(1):69-81.

4. Srinivas Rao Ch, Venkateswarlu V, Surender T, Eddleston M, Buckley NA. Pesticide poisoning in south India: opportunities for prevention and improved medical management. Trop Med Int Health. 2005 Jun; 10(6):581-8.

5. Dash SK, Aluri SR, Mohanty MK, Patnaik KK, Mohanty S. Sociodemographic profile of poisoning cases. JIAFM 2005;27(3):133-8.

6. Singh O, Javeri Y, Juneja D, Gupta M, Singh G, Dang R. Profile and outcome of patients with acute toxicity admitted in intensive care unit: Experiences from a major corporate hospital in urban India. Indian J Anaesth. 2011 Jul;55(4):370-4. doi: 10.4103/00195049.84860 .

7. Gargi J, Rai H, Chanana A, Rai G, Sharma G, Bagga IJ. Current trend of poisoning--a hospital profile. J Indian Med Assoc. 2006 Feb;104(2):72-3, 94.
8. Sheetu MKJ, Naik JD, Thakur MS, Langare SD, Pandey VO. Retrospective Analysis of poisoning cases admitted in a Tertiary Care Hospital. IJRTSAT 2014; $10(2): 365-8$.

9. Ramesha KN, Rao KB, Kumar GS. Pattern and outcome of acute poisoning cases in a tertiary care hospital in Karnataka, India. Indian J Crit Care Med. 2009 Jul-Sep;13(3):152-5. doi: 10.4103/0972-5229. 58541 .

10. Anthony L ,Kulkarni C. Patterns of poisoning and drug overdose and their outcome among in-patients admitted to the emergency medicine department of a tertiary care hospital. Indian J Crit Care Med 2012; 16(3):130-5.

11. S Alankar. A review on Peppermint oil. Asian Journal of Pharmaceutical and Clinical Research 2009; 2 (2):27-33.

12. Nath SS, Pandey C, Roy D. A near fatal case of high dose peppermint oil ingestion- Lessons learnt. Indian J Anaesth. 2012 Nov;56(6):582-4. doi: 10.4103 / 0019-5049.104585.

13. Kulkarni ML, Sreekar H, Keshavamurthy KS, Shenoy N. Jatropha curcas - poisoning. Indian J Pediatr. 2005 Jan;72(1):75-6.

14. Koltin D, Uziel Y, Schneidermann D, Kotzki S, Wolach B, Fainmesser P. A case of Jatropha multifida poisoning resembling organophosphate intoxication. Clin Toxicol (Phila). 2006;44(3):337-8.

15. Konradsen F, van der Hoek W, Cole DC, Hutchinson G, Daisley H, Singh S, Eddleston M. Reducing acute poisoning in developing countries-options for restricting the availability of pesticides. Toxicology. 2003 Nov 5;192(2-3):249-61.

16. FAO. International Code of Conduct on the Distribution and Use of Pesticides.FAO, Rome 2002.

\section{How to cite this article?}

Singh RR, Kumar A, Uraiya D, Dhaon P. Retrospective analysis of poisoning cases admitted in a tertiary care hospital in North Eastern UP, India. Int J Med Res Rev 2016;4 (7):1172-1177.doi: 10.17511/ijmrr.2016.i07.17. 